\title{
PEMETAAN ANGKA KEAMANAN LERENG DENGAN PENGARUH CURAH HUJAN DATA TROPICAL RAINFALL MEASURING MISSION
}

\author{
Ramadhani Febrian Dwinanda ${ }^{1)}$ R. Harya Dananjaya ${ }^{2)}$ Rr. Rintis Hadiani ${ }^{3)}$ \\ 1) Mahasiswa Fakultas Teknik, Program Studi Teknik Sipil, Universitas Sebelas Maret \\ 2), 3) Pengajar Fakultas Teknik, Program Studi Teknik Sipil, Universitas Sebelas Maret \\ Jln. Ir. Sutami 36A, Surakarta 57126; Telp. 0271-634524. \\ Email :masda95@gmail.com
}

\begin{abstract}
Landslide becomes the most natural disaster that occured oftenly in Indonesia. Indonesia considered to have a higher amount of rainfall that probably triggering a landslide. Areas that prone to landslide can be identified using safety factor map. SF map is easily to developed in this high technology era. Public will be more aware after accessing the SF map. The purpose of this research is to create landslide risk map of Ganoman Hill with influence of Tropical Rainfall Measuring Mission rain data.

To create SF map, this research uses soil parameter such as cohesion (c) and friction angle $(\varphi)$ value from undisturbed soil sample. This research also uses secondary data of soil mechanic property from previous research. The rainfall data observed by TRMM satellite was used as precipitation input parameter. These rain data was homogenic tested using RAPS and using Green-Ampt method to get saturated soil layer depth. The elevation and slope data was obtained from ASTER GDEM. To analysed slope stability, GeoStudio program is utilized. Further more, these SF values obtained from GeoStudio was used to create landslide risk map. The lower SF value, the higher risk to landslide.

The result of SF mapping shows that Bukit Ganoman, Koripan Village, Matesih District, Karanganyar Regency has several points that prone to landslide. The population areas and rice fields around Ganoman Hill are in stable area $(S F>1,25)$, nevertheless the crop field has several points with critical and unstable areas. There is segment of Matesih - Tawangmangu Primary Road that located on unstable areas (SF < 1,07) where the landslide was occured, so this research is proven to be valid enough as a reference for landslide mitigation in Ganoman Hill.
\end{abstract}

Keywords : Landslide, TRMM, GeoStudio, GIS, SF Mapping

Abstrak

Tanah longsor sudah menjadi bencana alam yang relatif sering terjadi di Indonesia. Curah hujan di Indonesia tergolong tinggi dan berpotensi memicu kelongsoran. Daerah rawan longsor dapat diketahui dengan peta safety factor. Saat ini teknologi sangat berkembang sehingga peta SF dapat dikembangkan dengan mudah. Masyarakat dapat lebih waspada dengan mengakses peta SF. Tujuan penelitian ini adalah untuk membuat peta keamanan lereng Bukit Ganoman dengan pengaruh curah hujan data Tropical Rainfall Measuring Mission.

Pembuatan peta SF pada penelitian ini memerlukan parameter tanah seperti nilai kohesi $(c)$ dan sudut gesek tanah $(\varphi)$ dari sampel tanah tidak terganggu. Penelitian ini juga memanfaatkan data sekunder sifat mekanis tanah penelitian sebelumnya. Data curah hujan hasil observasi satelit TRMM menjadi sumber nilai curah hujan. Curah hujan ini diuji homogenitas RAPS dan dianalisis dengan metode Green-Ampt untuk mendapatkan kedalaman tanah jenuh. Data ketinggian dan kemiringan didapat dari ASTER GDEM. Analisis kestabilan lereng menggunakan program GeoStudio. Selanjutnya, nilai-nilai $S F$ yang didapat dari program GeoStudio diolah untuk pembuatan peta kerawanan longsor. Semakin kecil nilai SF, maka semakin tinggi risiko kelongsoran.

Hasil penelitian pemetaan SF menunjukkan daerah Bukit Ganoman, Desa Koripan, Kecamatan Matesih, Kabupaten Karanganyar, memiliki beberapa titik yang rawan longsor. Lokasi pemukiman dan persawahan berada di daerah stabil (SF $>$ 1,25), namun perkebunan memiliki beberapa titik dengan $S F$ kategori kritis dan labil. Terdapat badan Jalan Raya Matesih Tawangmangu yang berada di titik dengan $S F$ labil $(S F<1,07)$ dimana lokasi tersebut mengalami kelongsoran sehingga penelitian ini terbukti cukup valid untuk dijadikan acuan mitigasi bencana tanah longsor di Bukit Ganoman.

Kata kunci : Tanah longsor, TRMM, GeoStudio, SIG, Pemetaan SF

\section{PENDAHULUAN}

Indonesia yang dilewati garis ekuator memiliki dua musim, yakni musim hujan dan musim kemarau. Menurut countryranker.com, Indonesia menjadi negara ketiga dengan curah hujan tertinggi di Asia Tenggara. Tanah longsor menjadi masalah utama yang sering terjadi pada musim hujan.

Pada tahun 2006 hingga 2017, tanah longsor terjadi setiap tahunnya di Kabupaten Karanganyar. Pada tanggal 5 Februari 2016 terjadi kelongsoran di Bukit Ganoman, Desa Koripan, Matesih, Karanganyar yang memutuskan akses jalan Matesih-Tawangmangu.

Nilai faktor keamanan (safety factor/SF) lereng mengindikasikan resiko terjadinya kelongsoran. Pemerintah Indonesia belum memiliki situs resmi yang menyajikan peta SF secara realtime. Penelitian ini menggunakan data near-realtime Tropical Rainfall Measuring Mission (TRMM) sebagai sumber data curah hujan. Curah hujan TRMM ini dianalisis untuk memunculkan lapisan tanah jenuh yang menjadi beban tambahan pada daerah Bukit Ganoman. 
Penelitian ini diharapkan dapat menjadi referensi untuk mitigasi bencana alam di Bukit Ganoman, Desa Koripan, Matesih, Karanganyar dan menjadi langkah awal terciptanya situs penyaji peta SF secara realtime.

\section{TINJAUAN PUSTAKA}

Penelitian mengenai stabilitas lereng sudah sering dilakukan, namun hanya beberapa penelitian yang memanfaatkan pemetaan. Dalam satu tahun terakhir, penelitian mengenai stabilitas lereng menggunakan program GeoStudio dan dipetakan dengan program SIG untuk menghasilkan peta SF dengan variasi resiko. Analisis kemiringan lereng dengan metode circle. Penelitian mengambil lokasi di Bukit Ganoman, Karanganyar, dengan menggunakan persentase tingkat kepercayaan, peta RBI, data tanah, dan kemiringan lereng sebagai parameter. Variabel hasil penelitian tersebut adalah nilai SF (Adriyati, dkk., 2016).

Penelitian serupa dilakukan dengan menganalisis stabilitas lereng dengan metode Morgenstern-Price dengan interval kepercayaan dan menghasilkan peta SF. Penelitian dengan lokasi yang sama yakni Bukit Ganoman dan menggunakan parameter berupa data elevasi dari ASTER GDEM dan interval kepercayaan. Penelitian ini juga menghasilkan variabel nilai $S F$ (Wicaksono, dkk., 2016).

\section{DASAR TEORI}

\section{Kelongsoran dan Stabilitas Lereng}

Longsor terjadi akibat gaya dorong yang lebih besar daripada gaya perlawanan pada bidang gelincir (Das, 1985). Menurut Hardiyatmo (2010), faktor keamanan lereng didapat melalui analisis stabilitas lereng yang membandingkan gaya penahan tanah dengan gaya penggerak. Stabilitas lereng sendiri dipengaruhi oleh faktor yaitu gaya yang menggerakkan, gaya rembesan dalam lereng, kemiringan bidang lereng, kuat geser tanah pada bidang gelincir, dan pengurangan kuat geser tanah pada bidang gelincir akibat tekanan hidrostatik.

\section{Tingkat Kepercayaan 95\%}

Tingkat kepercayaan menunjukkan seberapa besar nilai sampel dapat mengestimasi populasi dengan benar. Rumus yang digunakan dalam analisis tingkat kepercayaan 95\% ditunjukkan Persamaan 1 sampai Persamaan 3.

$$
\begin{aligned}
& \bar{x}=\mu=\frac{\sum_{i=1}^{n} x_{i}}{n}=\frac{x_{1}+x_{2}+\ldots+x_{n}}{n} \\
& \sigma=\sqrt{\frac{\sum_{i=1}^{n}\left(x_{i}-\mu\right)^{2}}{n-1}} \\
& \bar{x}-t_{(\alpha)} \frac{\sigma}{\sqrt{n}}<\mu
\end{aligned}
$$

Keterangan :

$$
\begin{array}{ll}
\mu & =\text { parameter rata-rata untuk distribusi, } \\
x_{n} & =\text { data ke- } n \\
n & =\text { banyaknya data, } \\
\sigma & =\text { standar deviasi, } \\
t & =\text { tabel Distribution Critical V } \text { alues, } \\
a & =\text { tingkat signifikan data. }
\end{array}
$$

\section{Tropical Rainfall Measuring Mission (TRMM)}

TRMM merupakan program kerjasama badan antariksa nasional $N A S A$ dan $J A X A$. Program ini bertujuan merekam data fenomena cuaca yang terjadi secara near-realtime dengan menggunakan sensor pada satelit. Data curah hujan yang dihasilkan satelit TRMM dapat diunduh dengan format raster tiff dan dapat diketahui nilainya dengan program GRASS GIS. Grid pada raster TRMM cukup besar dengan ukuran $30 \mathrm{~km} \times 30 \mathrm{~km}$ karena jangkauannya yang hampir global. Satu grid mewakili satu nilai curah hujan atau dapat dikatakan curah hujan tersebut merupakan curah hujan wilayah. Kemampuan satelit TRMM dapat melingkupi dari $35^{\circ}$ garis lintang utara hingga $35^{\circ}$ garis lintang selatan dengan ketinggian mengorbit pada $403 \mathrm{~km}$ di atas permukaan laut. Program TRMM ini telah dilanjutkan dengan program Global Precipitation Mission (GPM) pada pertengahan tahun 2015. Orbit satelit TRMM ditunjukkan pada Gambar 1. 


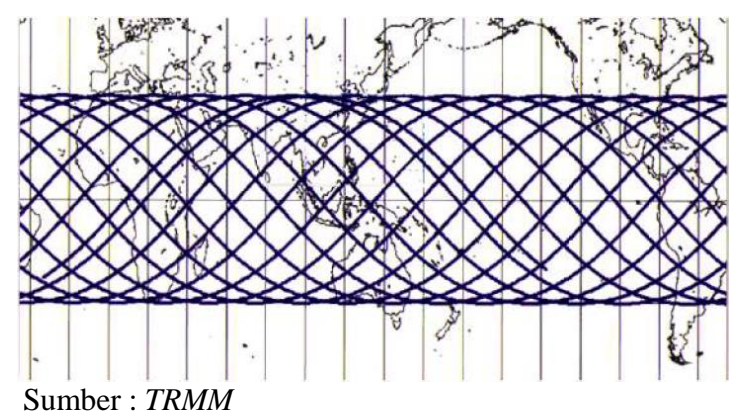

Gambar 1 Orbit Satelit TRMM

\section{Analisis Data Hujan}

Curah hujan data TRMM terlebih dahulu diuji homogenitasnya dengan metode RAPS sebelum dianalisis lebih lanjut. Data hujan yang digunakan selama 12 bulan dari bulan Maret 2015 hingga Februari 2016. Metode $R A P S$ tersebut dilakukan dengan membandingkan $Q_{R A P S}$ dan $R_{R A P S}$ antara nilai hitung dan nilai kritik sesuai dengan nilai Confidence Interval. Data dikatakan homogen apabila nilai hitung lebih kecil dari nilai kritik. Jika sebaliknya, maka data dengan nilai ekstrim diganti dengan nilai rerata atau batas atas/bawah (Haan, 1977).

Curah hujan yang diunduh dari situs TRMM berupa data curah hujan harian, sehingga perlu diolah untuk menjadi curah hujan per jam. Penelitian ini menggunakan curah hujan dua harian maksimum. Analisis intensitas hujan Mononobe digunakan untuk mengubah curah hujan harian menjadi hujan per jam dengan durasi hujan selama 6 jam. Rumus untuk metode Mononobe ditunjukkan pada Persamaan 4.

$$
I=\frac{R_{24}}{24}\left(\frac{24}{t}\right)^{2 / 3}
$$

Keterangan :

$I \quad=$ intensitas hujan untuk durasi $t \mathrm{jam}(\mathrm{mm} / \mathrm{jam})$,

$\mathrm{R}_{24}=$ curah hujan maksimum 24 jam,

$t \quad=$ durasi hujan (jam).

Besar nilai $t$ ditentukan berdasarkan rata-rata durasi hujan maksimum yang terjadi dalam satu hari pada suatu lokasi (Kalimanto, dkk., 2015). Menurut Nurhidayah (2010), Kabupaten Karanganyar pernah mengalami hujan dengan durasi maksimum 6 jam.

\section{Analisis Kedalaman Tanah Jenuh Green-Ampt}

Metode infiltrasi Green-Ampt digunakan untuk menduga kapasitas dan laju infiltrasi. Laju infiltrasi merupakan fungsi dari parameter hidraulik tanah yaitu permeabilitas tanah, suction head, dan kelembaban tanah. Tebal tanah jenuh muncul akibat hujan yang terjadi selama $t$ jam. Rumus untuk mendapatkan tebal tanah jenuh yang digunakan dalam penelitian ini ditunjukkan pada Persamaan 5 dan Persamaan 6. Persamaan 5 menggunakan trial numerik untuk mendapatkan nilai $F(t)$.

$$
\begin{aligned}
& t=\left(t_{p}-t_{s}\right)+\frac{1}{k \cos \alpha}\left[F(t)-\frac{\psi\left(\theta_{s}-\theta_{i}\right)}{\cos \alpha} \ln \left(1+\frac{F(t) \cos \alpha}{\psi\left(\theta_{s}-\theta_{i}\right)}\right)\right] \text { untuk } F(t)>F_{p} \\
& H_{\text {sat }}=\frac{F(t)}{\left(\theta_{s}-\theta_{i}\right)}
\end{aligned}
$$

Keterangan :

$F_{p}=F(t)=$ jumlah air terinfiltrasi sebelum air menggenang di muka tanah $(\mathrm{cm})$,

$k \quad=$ koefisien permeabilitas $\tan a h(\mathrm{~cm} / \mathrm{jam})$,

$t \quad=$ durasi hujan (jam),

$a \quad=$ sudut kemiringan lereng (derajat),

$\theta_{s} \quad=$ kelembaban tanah jenuh,

$\theta_{i} \quad=$ kelembaban tanah awal sebelum infiltrasi,

$\psi \quad=\operatorname{suction}$ head $(\mathrm{cm})$,

$H_{\text {sat }}=$ ketebalan tanah jenuh $(\mathrm{cm})$. 
Nilai konduktivitas dan suction head diambil berdasarkan Tabel 1.

Tabel 1 Parameter infiltrasi Green-Ampt untuk berbagai jenis tanah (Rawles, dkk., 1983)

\begin{tabular}{lccccc}
\hline Texture & $\begin{array}{c}\text { Porosity } \\
(\eta)\end{array}$ & $\begin{array}{c}\text { Residual Po- } \\
\text { rosity } \\
\left(\theta_{r}\right)\end{array}$ & $\begin{array}{c}\text { Effective Poros- } \\
\text { ity } \\
\left(\theta_{e}\right)\end{array}$ & $\begin{array}{c}\text { Suction Head } \\
\psi(\mathrm{cm})\end{array}$ & $\begin{array}{c}\text { Conductivity } \\
(\mathrm{cm} / \mathrm{hr})\end{array}$ \\
\hline Sand & 0,437 & 0,020 & 0,417 & 4,95 & 11,78 \\
\hline Loamy sand & 0,437 & 0,036 & 0,401 & 6,13 & 2,99 \\
\hline Sandy loam & 0,453 & 0,041 & 0,412 & 11,01 & 1,09 \\
\hline Loam & 0,463 & 0,029 & 0,434 & 8,89 & 0,34 \\
\hline Silt loam & 0,501 & 0,015 & 0,486 & 16,68 & 0,65 \\
\hline Sandy clay loam & 0,398 & 0,068 & 0,330 & 21,85 & 0,15 \\
\hline Clay loam & 0,464 & 0,155 & 0,309 & 20,88 & 0,10 \\
\hline Silty clay loam & 0,471 & 0,039 & 0,432 & 27,30 & 0,10 \\
\hline Sandy clay & 0,430 & 0,109 & 0,321 & 23,90 & 0,06 \\
\hline Silty clay & 0,470 & 0,047 & 0,423 & 29,22 & 0,05 \\
\hline Clay & 0,475 & 0,090 & 0,385 & 31,63 & 0,03 \\
\hline
\end{tabular}

\section{Analisis Stabilitas Lereng program GeoStudio}

Nilai SF diketahui berdasarkan hasil analisa stabilitas lereng metode Morgenstern-Price melalui program GeoStudio. Metode Morgenstern-Price merupakan metode analisis stabilitas lereng yang menggunakan asumsi sama seperti metode kesetimbangan batas umum yaitu asumsi adanya hubungan gaya geser antar irisan dan gaya normal antar irisan. Persamaan umum kesetimbangan batas ditunjukkan pada Persamaan 7.

$$
X=\lambda f(x) E
$$

\section{Keterangan :}

$$
\begin{array}{ll}
X & =\text { gaya geser antar irisan, } \\
\lambda & =\text { faktor pengali (desimal) } \\
f(x) & =\text { fungsi, } \\
E & =\text { gaya normal antar irisan. }
\end{array}
$$

Persamaan untuk faktor keamanan prinsip kesetimbangan momen dan kesetimbangan gaya ditunjukkan pada Persamaan 8 dan Persamaan 9.

$$
\begin{aligned}
& F_{m}=\frac{\sum\left(c^{\prime} l+(P-u l) \tan \phi\right)}{\sum W \sin \alpha} \\
& F_{f}=\frac{\sum\left(c^{\prime} l+(P-u l) \tan \phi\right) \cos \alpha}{\sum P \sin \alpha}
\end{aligned}
$$

Keterangan :

$$
\begin{array}{ll}
F_{m} & =\text { faktor keamanan prinsip kesetimbangan momen } \\
F_{f} & =\text { faktor keamanan prinsip kesetimbangan gaya, } \\
c & =\text { kohesi, } \\
P & =\text { gaya normal, } \\
\phi & =\text { sudut gesek dalam }, \\
\alpha & =\text { sudut inklinasi. }
\end{array}
$$

Persamaan-persamaan tersebut membutuhkan proses iterasi dan asumsi untuk mendapatkan nilai $S F$ sehingga digunakan program GeoStudio. Pemodelan dibuat menyesuaikan kemiringan lereng beserta tebal tanah jenuh pada kemiringan tersebut. Nilai SF yang dihasilkan merupakan nilai SF pada satu sel raster sesuai kemiringan dan tanah jenuhnya.

\section{Pemetaan $S F$}

Pembuatan peta SF dilakukan dengan program GRASS GIS dan memanfaatkan file comma separated values dimana berisi nilai SF dan koordinat x dan y. Pemetaan dilengkapi dengan unsur topografi berdasarkan peta RBI untuk mengetahui lahan yang patut diwaspadai. 


\section{METODOLOGI PENELITIAN}

Metode yang digunakan penelitian ini meliputi pengujian lab untuk sampel tanah undisturbed yang diambil langsung dari lokasi oleh peneliti sebagai data primer. Data sekunder dari penelitian sebelumnya berupa data fisik dan mekanik tanah. Data tanah tersebut digunakan untuk analisis tebal tanah jenuh Green-Ampt.

Data curah hujan wilayah harian TRMM selama 12 bulan (Maret 2015 hingga Februari 2016) diuji homogenitasnya dengan metode RAPS. Jika homogen, maka selanjutnya mengambil data curah hujan dua harian maksimum lalu diubah menjadi hujan jam-jaman dengan metode Mononobe durasi hujan 6 jam. Intensitas hujan ini selanjutnya diolah untuk mendapatkan tebal tanah jenuh.

Data ASTER GDEM diolah untuk mengetahui kemiringan pada setiap grid. Selanjutnya tebal tanah jenuh diketahui dengan menganalisis data tanah, intensitas hujan, dan kemiringan. Pada program GeoStudio, analisis stabilitas lereng dilakukan dengan memodelkan lereng menyesuaikan kemiringan dan tanah jenuh yang terbentuk serta meng-input data tanah. Nilai $S F$ hasil analisis berupa nilai $S F$ pada satu grid. Kemudian dipetakan dengan program GRASS GIS untuk disatukan dengan SF pada grid lainnya serta ditambahkan unsur topografi dari peta RBI. Penelitian ini memanfaatkan program Microsoft Excel, GeoStudio, dan GRASS GIS.

\section{HASIL DAN PEMBAHASAN}

Hasil dari penelitian ini berupa peta $S F$ yang ditunjukkan pada Gambar 2.

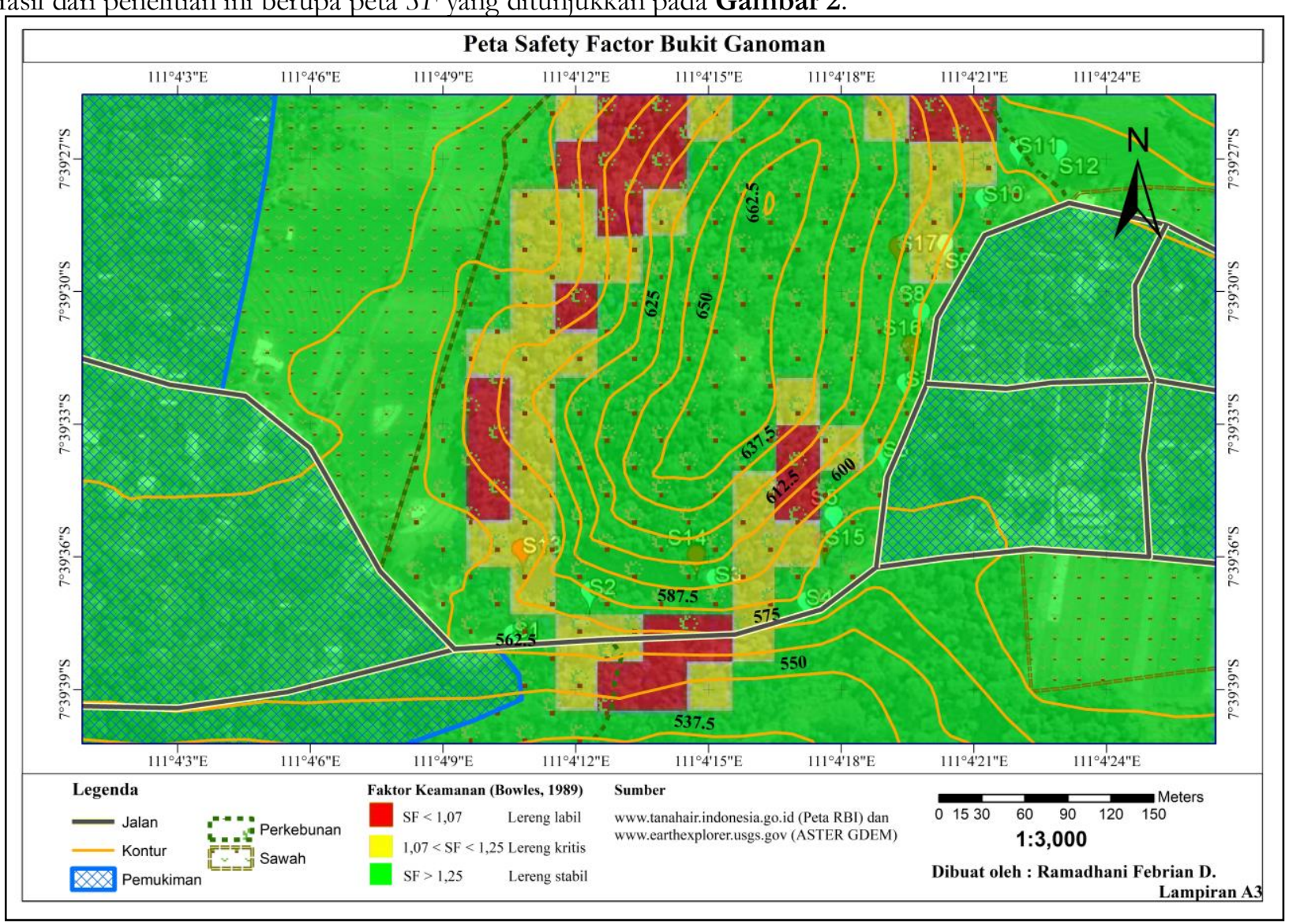

Gambar 2 Peta Safety Factor

Peta $S F$ menunjukkan bahwa Bukit Ganoman memiliki daerah dengan kondisi stabil $(S F>1,25)$, kritis $(1,07<$ $S F<1,25)$, dan labil $(S F<1,07)$. Lahan pemukiman dan persawahan berada di daerah dengan kondisi stabil. Sementara lahan perkebunan memiliki beberapa titik dengan kondisi kritis dan labil.

\section{KESIMPULAN}

Dari penelitian ini dapat disimpulkan bahwa :

1. Peta SF menunjukkan bahwa Bukit Ganoman memiliki beberapa titik dengan kondisi labil $(S F<1,07)$, kritis $(1,07<S F<1,25)$, dan stabil $(S F>1,25)$. Terdapat badan Jalan Raya Matesih-Tawangmangu yang berada pada daerah labil.

2. Daerah lereng stabil berupa sawah, pemukiman, dan banyak titik di perkebunan.

3. Daerah lereng kritis rata-rata berada di sekeliling Bukit Ganoman berupa lahan perkebunan. 
4. Daerah lereng labil berada di beberapa titik lahan perkebunan seperti bagian Selatan dan Barat Laut Bukit Ganoman.

\section{REFERENSI}

Adriyati, Meilani, R. Harya Dananjaya, dan Niken Silmi Surjandari. 2016. Analisis Stabilitas Lereng Menggunakan Software Geo Studio 2007 dengan Variasi Kemiringan (Studi Kasus : Bukit Ganoman Kab. Karanganyar). E-Jurnal Matriks Teknik Sipil/Maret 2017/97. Surakarta : UNS.

Amir. 2015. http://www.countryranker.com/countries-with-highest-average-annual-rainfall/. Diakses 26 Oktober 2017 pukul 16:08 WIB.

Chen, Li, dan Young, Michael, H.., 2006. Green-Ampt Infiltration Model for Sloping Surfaces. Water Resources Research, Vol. 42, W07240. Las Vegas : Division of Hydrologic Sciences, Desert Research Institute.

Das, Braja M., 1985. Principles of Geothecnical Engineering, 3rd ed. Carbondale : Southern Illinois University, PWS Publishing Company, Boston.

GEO-SLOPE International Ltd., 2015. Stability Modelling with SLOPE/W. Canada.

Haan, Charles, Thomas, 1977. Statistical Methods in Hydrology. Iowa : The Iowa State University Press.

Hardiyatmo, Hary, Christadi, 2010. Mekanika Tanah 1. Yogyakarta : UGM Press.

Kalimanto, Demarda, Niken Silmi Surjandari, dan R. Harya Dananjaya, 2015. Analisis Stabilitas Lereng Akibat Beban Hujan Harian Maksimum Bulanan dan Beban Lalu Lintas. E-Jurnal Matriks Teknik Sipil/Juni 2016/458. Surakarta: UNS.

Nurhidayah, Ropri, Mamok Suprapto R., dan Siti Qomariyah, 2010. Kajian Angkutan Sedimen pada Sungai Bengawan Solo (Serenan-Jurug). E-Jurnal Matriks Teknik Sipil/Juni 2013/69. Surakarta: UNS.

Rawls, Walter, J., dkk., 1983. Green-Ampt Infiltration Parameters from Soils Data. Inggris: J. Hydraul.

Syaifullah, M. D., 2014. "Validasi Data TRMM terhadap Data Curah Hujan Aktual di Tiga DAS di Indonesia". Jurnal Meteorologi dan Geofisika Vol 15 No.2.

Tawakkal, M. Zikry, Niken Silmi Surjandari, dan R. Harya Dananjaya, 2016. Pengaruh Curah Hujan Harian Maksimum Bulanan terhadap Stabilitas Lereng (Studi Kasus : Desa Mangunbarjo, Jatipurno, Wonogiri). E-Jurnal Matriks Teknik Sipil/Juni 2016/445. Surakarta : UNS.

Triatmodjo, Bambang, 2008. Hidrologi Terapan. Yogyakarta : Beta Offset.

Wicaksono, Nyco Maulana, R. Harya Dananjaya, dan Niken Silmi Surjandari. 2016. Pemanfaatan Data Digital Elevation Model (DEM) untuk Pemetaan Angka Keamanan Lereng Berdasarkan Resiko Longsor dari Tinjauan Geoteknik. E-Jurnal Matriks Teknik Sipil/Maret 2017. Surakarta : UNS. 